\title{
Screening and characterization of endophytic fungi as antagonistic agents toward Fusarium oxysporum on eggplant (Solanum melongena)
}

\author{
FAJAR RAHMAH NURAINI, RATNA SETYANINGSIH ${ }^{\boldsymbol{\eta}}$, ARI SUSILOWATI \\ Department of Biology, Faculty of Mathematics and Natural Sciences, Universitas Sebelas Maret. Jl. Ir. Sutami 36A Kentingan Surakarta 57126, Central \\ Java, Indonesia. Tel/Fax. +62-271-663375 ’email: ratnasetya@yahoo.co.id
}

Manuscript received: 18 May 2017. Revision accepted: 27 August 2017.

\begin{abstract}
Nuraini FR, Setyaningsih R, Susilowati A. 2017. Screening and characterization of endophytic fungi as antagonistic agents toward Fusarium oxysporum on eggplant (Solanum melongena). Biodiversitas 18: 1377-1384. Fusarium oxysporum is a soil borne pathogenic fungus that causes wilt disease in members of the family Solanaceae including the eggplant (Solanum melongena L.). One approach to resolving the problem of wilt disease in eggplant is to find endophytic microbes with antagonistic activity against $F$. oxysporum. The study reported here aimed to isolate such endophytic fungal antagonists from growing eggplants, to determine their antagonistic mechanisms, and to identify them. Samples of pathogenic fungi from diseased plants, assumed to be $F$. oxysporum, were obtained from the Laboratory of Plant Pests and Diseases of the Faculty of Agriculture, Universitas Sebelas Maret Surakarta. These were used to evaluate the antagonistic potential of endophytic fungi obtained from healthy eggplants in Dawung Village, Matesih, Karanganyar, Central Java. Specimens of various plant parts were collected from the healthy eggplants. The surfaces of these samples were sterilized for four minutes to remove contaminants, and then crushed excisions were cultured on a potato dextrose agar (PDA) medium. Antagonistic tests between endophytic and pathogenic fungi used the agar plug diffusion technique. Identification of fungi isolates was carried out on the basis of morphological characteristics. Six endophytic fungi isolated had antagonist activity against $F$. oxysporum. The antagonistic mechanism of FEB1, FEB2, FEB5 and FED1 was competition; FED2 was antibiosis, and FED3 was parasitism. Based on their morphological characteristics, FEB2, FEB5 and FED3 were identified as Helicomyces spp.; FEB1 was a Rhizopus sp.; FED1 was a Mucor sp.; and FED2 was a species of Penicillium.
\end{abstract}

Keywords: Solanum melongena, Fusarium oxysporum, endophytic fungi, antagonistic

\section{INTRODUCTION}

Eggplant (Solanum melongena L.) is a vegetable crop that can be grown in the tropics and subtropics (Daunay and Janick 2007). The nutritional content of the fresh fruit is good: it is low in calories, fat, and sodium; and contains a favorable balance of protein, starch, fiber and additional nutrients such as potassium, magnesium, folic acid, vitamin B6, and vitamin A (Erica 2011). Extracts from the skin of the purple eggplant have the effect of lowering blood sugar levels (Aer et al. 2013). Anticancer activity has been identified in hepatocellular carcinoma, owing to the presence of steroidal alkaloids and sterol glycoside compounds (Shabana et al. 2013). Based on data from the Central Bureau of Statistics (2015), eggplant vegetable crop production in Indonesia has fluctuated little over the period 2011 to 2014; the production decreased from 519,481 tons in 2011 to 518,827 tons in 2012 but increased to 557,053 tons in 2014 .

One of the diseases that attack eggplant is wilt disease caused by a soil-borne pathogen, namely the fungus Fusarium oxysporum (Fo). The symptoms include the plant looking wilted and yellowish, and its vascular tissue developing a brown color (Yildiz et al. 2012). Plant productivity declines. An effective, economical and practical, way to control wilt disease has not been discovered. Crop rotation, use of disease resistant varieties, sterilizing or solarizing the soil, and use of fungicides have all been recommended at times to deal with the disease (Agrios 1988; Dikilitas and Kocyigit 2010; Yildiz et al. 2012). Fusarium oxysporum (Fo) produces chlamydospores which can last a long time in the soil even when extreme environmental conditions constrain other microorganisms (Agrios 1988). Therefore, Fo is a fungal pathogen of eggplant that is difficult to control. One potential approach to addressing the problem of wilt disease in eggplant is to identify and use endophytic microbial isolates with activity antagonistic to the development of the pathogen.

Endophytes are microbes that inhabit higher plants. Endophytes are often considered as sources of novel metabolites with potential for medical, agriculture, and/or industrial exploitation. Natural products from endophytic microbes have been observed to inhibit or kill a wide variety of harmful diseases-causing agents, including bacteria, fungi, viruses and protozoa that affect humans, animals, and plants (Strobel and Daisy 2003). Endophytic fungi have proved to be the most promising. Many have been accessed as sources of bioactive compounds that can be used for treatment of a number of diseases (Kumar et al. 2014). Many plants in nature appear to be symbiotic with fungal endophytes. These endophytic fungi have a high diversity, with various impacts on plants (Rodriguez et al. 2009). The purposes of the study reported in this paper were to obtain endophytic fungi having antagonistic 
activity against Fo from eggplant, to determine their antagonistic mechanisms, and to identify them.

\section{MATERIALS AND METHODS}

\section{Sampling area and materials}

Endophytic fungi were isolated from healthy eggplant crops derived from Dawung Village, Matesih, Karanganyar, Central Java, Indonesia. Fusarium (Fo) isolates pathogenic towards eggplant were obtained from the Laboratory of Plant Pests and Diseases of the Faculty of Agriculture, Universitas Sebelas Maret Surakarta. These isolates of the pathogen ( $\mathrm{Fo}$ ) derived from diseased eggplants in Karanglo Village, Matesih. The medium used to test antagonism of the endophytic fungal isolates again Fo was potato dextrose agar (PDA).

\section{Procedures}

Sampling of healthy eggplant crop as a source of endophytic fungi

Three eggplant plants were sampled from three different random points in crops in Dawung Village. Specimens of roots, stems, and leaves were taken from the plants. The abiotic factors measured at the site were $\mathrm{pH}$ of the soil, air temperature, soil temperature, soil humidity, and air humidity.

\section{Isolation and purification of endophytic fungi}

Specimens of the plant parts were cleaned under running water and cut into $\pm 5 \times 5 \mathrm{~cm}$ sections. The surfaces of the specimens were sterilized by soaking in an emulsion of $70 \%$ ethanol for 4 minutes; $\mathrm{NaClO} 5.25 \%$ for 4 minutes; and sterile distilled water three times each for 1 minute. Samples, $1 \mathrm{~cm}^{2}$ in size, excised from the specimens were then crushed and plated out on PDA media. Separated fungal colonies that grew were purified on new PDA medium.

\section{Identification of Fusarium oxysporum ( $F o$ ) isolates}

Eight isolates of the pathogenic fungi from eggplants with symptoms of Fusarium disease, coded C1, C2, C3, C4, C5, C6, C7 and C8, were identified macroscopically and microscopically for the presence of Fusarium oxysporum (Fo) based on Gandjar et al. (1999) and Watanabe (2002).

\section{Endophytic fungi screening using agar plug diffusion method}

The screening method used for assessment of antagonism was a modification of the agar plug diffusion method (Sharma et al. 2011; Balouiri et al. 2015). For the test of antagonistic activity of the endophytic fungi against the Fo pathogenic fungi, both were grown and incubated for 3 days. Samples, $6 \mathrm{~mm}$ in diameter, from both the Fo isolate and one of each of the endophyte isolates were then placed on a new PDA medium. The two isolate samples were separated by a distance of $3 \mathrm{~cm}$ on the medium. Cultures were then incubated for 7 days at the temperature of $25^{\circ} \mathrm{C}$.
The percentage of growth inhibition of the Fo pathogenic fungi were categorized as follows; $<30 \%=$ low antifungal activity, $30-<50 \%=$ moderate antifungal activity, $50-<70 \%=$ high antifungal activity, and $\geq 70 \%=$ very high antifungal activity (Živković et al. 2010; Khrueayu and Pilantanapak 2012). The percentage inhibition was calculated based on the formula of Kurnia et al (2014).

$$
\mathrm{I}:=\frac{\mathrm{r}_{1}-\mathrm{r}_{2}}{\mathrm{r}_{1}} \quad \mathrm{X} 100 \%
$$

Where:

$\mathrm{I}=$ the percentages inhibition $(\%)$

$\mathrm{r}_{1}=$ the radial growth of the Fo pathogen away from endophyte $(\mathrm{mm})$

$\mathrm{r}_{2}=$ the radial growth of the Fo pathogens toward endophyte $(\mathrm{mm})$

\section{Observation of antagonistic mechanisms}

Inhibition mechanisms of endophytic fungi against the Fo pathogenic fungi were observed macroscopically and microscopically. The macroscopic observation was conducted by observing the interaction between endophytic fungi and Fo in a Petri dish. The mechanism of inhibition that occurred could be identified based on Baker and Cook (1983). Microscopic observation was conducted to detect the meeting between the hypha of the endophytic fungi with the pathogen, or else to detect changes in the hypha of the pathogen due to the influence of the active compounds produced by endophytic fungi. The way it worked was that a part of each PDA medium that had been inoculated with both endophytic fungi and pathogenic fungi isolates was cut and dripped with lactophenol. Afterward, the preparations were observed under a microscope (Kurnia et al. 2014).

\section{Morphological characterization of potential endophytic microbes}

Endophytic fungi were characterized macroscopically and microscopically. Fungal isolates were characterized based on Watanabe (2002).

\section{RESULTS AND DISCUSSION}

\section{Sampling locations of healthy eggplant crops}

The total area of Dawung is \pm 256.6040 Ha. Dawung Village includes areas that are located in the uplands $( \pm 370$ masl $)$ with rainfall $\pm 2,000 \mathrm{~mm} /$ year (Dawung Village Monograph Data 2013). Dawung Village has soil and air temperatures between $25-33^{\circ} \mathrm{C}$, soil and air humidity around $64-88 \%$, and soil $\mathrm{pH}$ ranging from 6.8 to 7.4 (Table 1). The temperature range in Dawung Village where the samples were taken supports the growth of eggplant crops, since eggplants are commonly grown in a temperature range of $22-30^{\circ} \mathrm{C}$ (Andersen 2011), a humidity of $85-90 \%$ (Delahaut and Newenhouse 1997), and a soil pH 
of 6.0 to 7.0 (Andersen 2011). Fo has an optimum temperature of growth about $25^{\circ} \mathrm{C}$ while its optimum $\mathrm{pH}$ for growth is about 8 (Fayzalla et al. 2008). Temperatures in Dawung Village support the growth of Fo but the neutral soil $\mathrm{pH}$ condition is perhaps less than optimal for the growth of Fo.

\section{Endophytic fungal isolates}

Samples of the healthy eggplant crop being used, were four months old. The eggplant crops at that age are usually in good condition, not too young or too old. From the specimens taken from plant parts, six endophytic fungi isolates were obtained (Table 2).

\section{Isolates of Fusarium oxysporum (Fo)}

The identification of the putative Fusarium isolates obtained from the diseased field showed that the $\mathrm{C} 2$ isolate was, in fact, Fusarium oxysporum. Its macroscopic characters included circularly shaped colonies, flat elevation, colony edges, purple-colored smooth colony profile, aerial mycelia in moderate numbers and white color. The diameter of the colony reached $60.0 \mathrm{~mm}$ on the $7^{\text {th }}$ day and the growth rate reached $8.6 \mathrm{~mm}$ /day (Figure 1A). In addition to the macroscopic characters, its microscopic characters included elongated and curved macroconidia with a slightly tapered tip. The macroconidia had 4 cells sized $30.3 \mathrm{~m} \times 3.6 \mathrm{~m}$ (Figure 1C and 1D). Microconidia had 1-2 cells with or without septa and size of $11.6 \mathrm{~m} \times 3.2 \mathrm{~m}$ (Figure $1 \mathrm{~B}$ and 1E). The $\mathrm{C} 2$ isolate had two kinds of chlamydospores namely intercalary chlamydospores and terminal chlamydospores. The diameter of the chlamydospores was $5.6 \mathrm{~m}$ (Figure $1 \mathrm{~F}$ and $1 \mathrm{G)}$.

\section{Activities of endophytic fungi as antagonistic agents}

From the screening results, six endophytic fungal isolates with antagonistic potential were obtained. The percentage inhibition at 7 dai (days after inoculation) for these six isolates was more than $50 \%$. Therefore, they were classified in the category of high antifungal activity (Table 3).

Isolate FED1 had a very high antifungal activity while isolates FEB1, FEB2, FEB5, FED2, and FED3 were categorized as having high antifungal activity. Overall, the percentage inhibition by endophytic fungi increased up to 7 dai. Six of the endophyte isolates exhibited visible signs of antagonistic mechanisms such as antibiosis, parasitism, and competition (Figure 2). and

Isolates FEB1, FEB2, FEB5, and FED1were antagonistic towards Fo by a competition mechanism. Those four isolates competed with Fo for food resources and space as indicated by the dominance of endophytic fungi in the Petri dishes (Figures 2B-E). Fo nutritional needs were disrupted by the mechanism of competition, causing a decline in the germination percentage of its spores by as much as 20-30\% (a phenomenon described by Berlian et al. 2013). The FED2 isolate achieved inhibition by an antibiosis mechanism as indicated by the zone of inhibition in Figure 2F. The FED3 isolate acted as a parasite of Fo because its hyphae grew over the Fo hyphae (Figure 2G).

According to Dolakatabadi et al. (2012), endophytic fungi can form hooks around the hyphae of fungal pathogens before penetration, or sometimes can directly penetrate into the area of the fungal pathogens. Kurnia et al. (2014) explains that the hyphae of fungi pathogens undergo malformations into spiral, curved, irregular shapes, and experience a shortening, due to the exposure to the active compounds produced by endophytic microbes.

Figure 3A shows normal hypha that grew straight lengthwise. On the other hand, FEB1 hyphae were wrapped around the Fo hyphae, then directly penetrated into the Fo area (see Figure 3B). Isolates FEB2 and FED1 formed a hyphal structure that looked like a hook and wrapped around the Fo hypha (Figure 3C and 3E). FEB5 and FED3 hypha ensnared Fo (3D and $3 \mathrm{G}$ ). Fo hypha underwent shortening, breakage, and crimping, presumably due to active compounds produced by FED2 (Figure 3F).

Table1. The abiotic factors at the sampling site

\begin{tabular}{llll}
\hline \multicolumn{1}{c}{ Parameter } & \multicolumn{3}{c}{ Sampling time } \\
& Morning & Afternoon & Evening \\
\hline Soil temperature $\left({ }^{\circ} \mathrm{C}\right)$ & 25.5 & 31.3 & 26.0 \\
Air temperature $\left({ }^{\circ} \mathrm{C}\right)$ & 28.1 & 32.5 & 26.8 \\
Soil humidity $(\%)$ & 84.0 & 74.3 & 80.0 \\
Air humidity $(\%)$ & 84.3 & 64.7 & 87.5 \\
Soil pH & 6.8 & 6.8 & 7.0 \\
\hline
\end{tabular}

Tabel 2. Endophytic fungi isolated from Solanum melongena

\begin{tabular}{lll}
\hline Part of plant & \multicolumn{1}{c}{$\begin{array}{c}\text { Codes given to identify the } \\
\text { endophyte isolates }\end{array}$} & $\begin{array}{c}\text { No. of } \\
\text { isolates }\end{array}$ \\
\hline Roots & FEA1 & 1 \\
Stems & FEB1, FEB2, FEB3, FEB4, FEB5 & 5 \\
Leaves & FED1, FED2, FED3 & 3 \\
Total isolates & & 9 \\
\hline
\end{tabular}

Table 3. Percentage growth inhibition of Fusarium oxysporum $\mathrm{C} 2$ resulting from antagonism by endophytic fungi isolated from Solanum melongena

\begin{tabular}{lllllll}
\hline Isolate & \multicolumn{6}{c}{ Percentage of inhibition (\%) } \\
& 2 dai & 3 dai & 4 dai & 5 dai & 6 dai & 7 dai \\
\hline FEA1 & 6.3 & 7.3 & 13.2 & 26.7 & 33.6 & 40.8 \\
FEB1 & 24.2 & 38.4 & 57.7 & 61.8 & 68.0 & 68.6 \\
FEB2 & 15.3 & 46.8 & 59.2 & 63.8 & 69.0 & 68.5 \\
FEB3 & 3.5 & 5.9 & 22.0 & 37.5 & 40.0 & 48.1 \\
FEB4 & 5.0 & 4.2 & 10.3 & 25.5 & 39.0 & 43.2 \\
FEB5 & 11.7 & 24.4 & 44.4 & 55.6 & 60.1 & 62.9 \\
FED1 & 24.7 & 41.9 & 63.2 & 71.8 & 75.6 & 73.4 \\
FED2 & 9.2 & 14.8 & 25.4 & 36.0 & 43.5 & 50.2 \\
FED3 & 9.3 & 10.5 & 23.5 & 42.0 & 47.9 & 50.3 \\
\hline
\end{tabular}



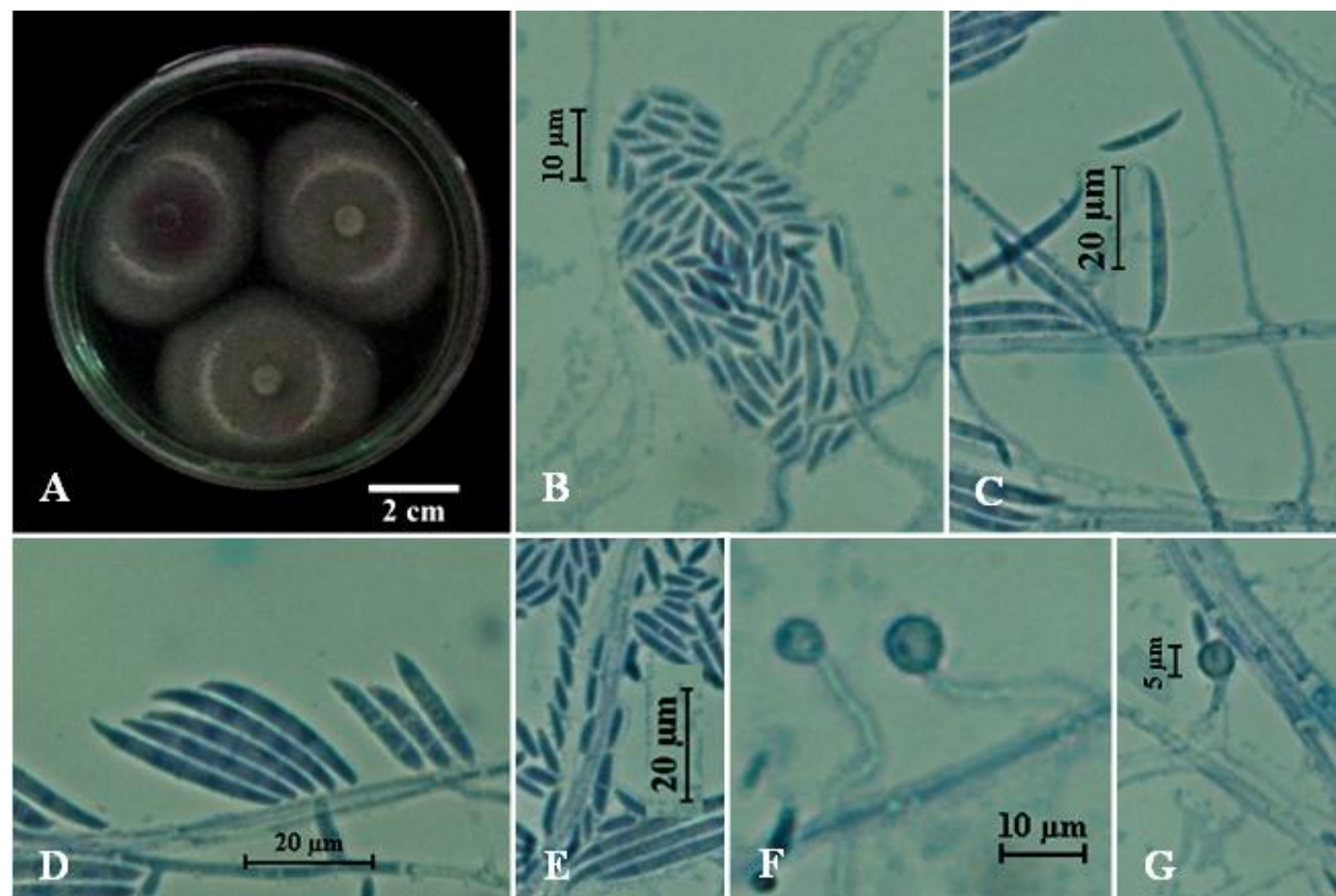

Figure 1. Fusarium oxysporum $\mathrm{C} 2$ (Fo); (A) colony on PDA medium incubated 7 days in the dark, (B and E) microconidia, (C and D) macroconidia and $(\mathrm{F}$ and $\mathrm{G})$ chlamydospores.

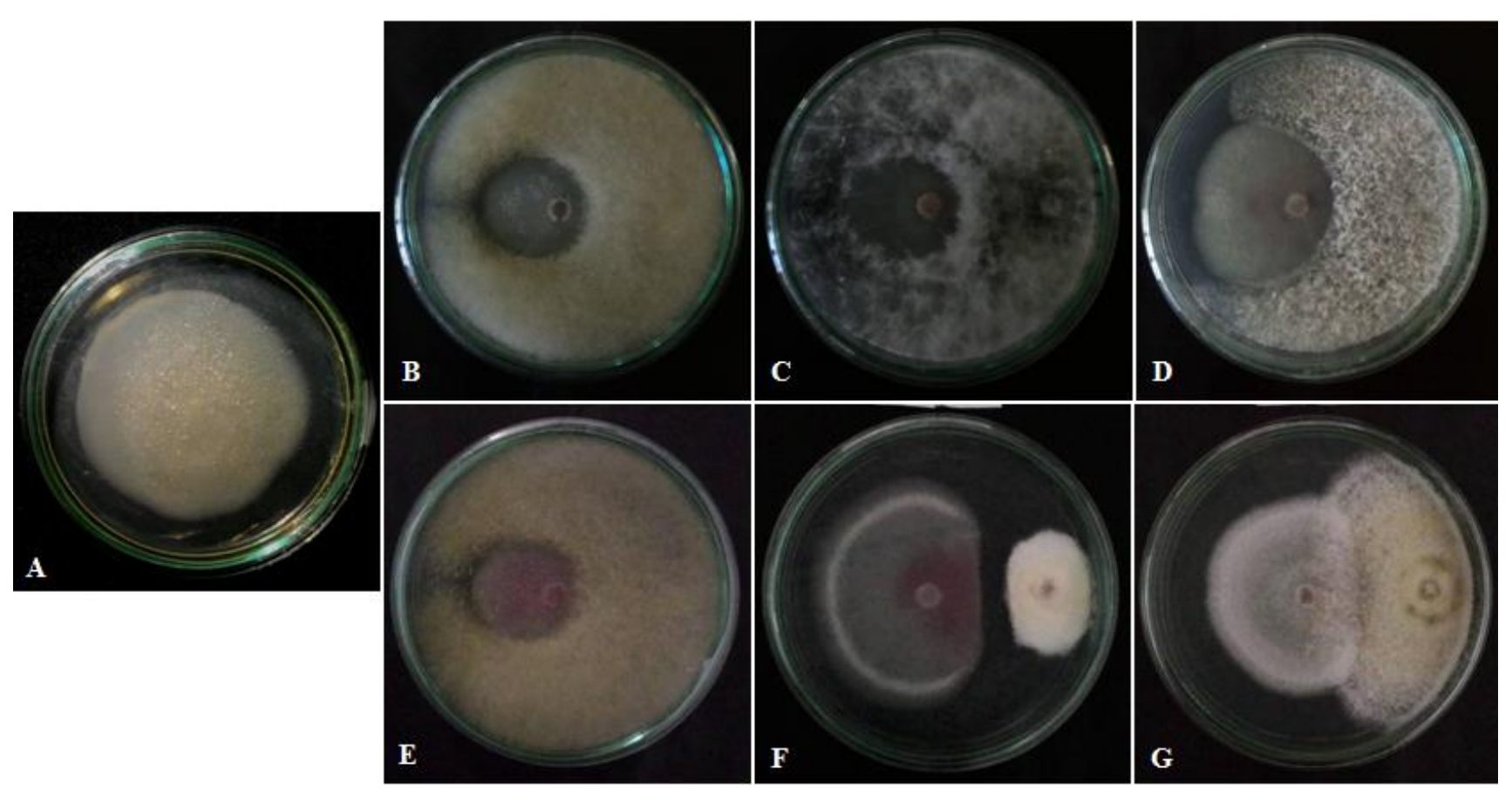

Figure 2. Inhibition of Fusarium oxysporum $\mathrm{C} 2$ by endophytic fungi isolated from Solanum melongena. (A) F. oxysporum control; (BG) endophytic fungi tests - (B) FEB1, (C) FEB2, (D) FEB5, (E) FED1, (F) FED2, and (G) FED3. All cultures incubated for 7 days on PDA media. 


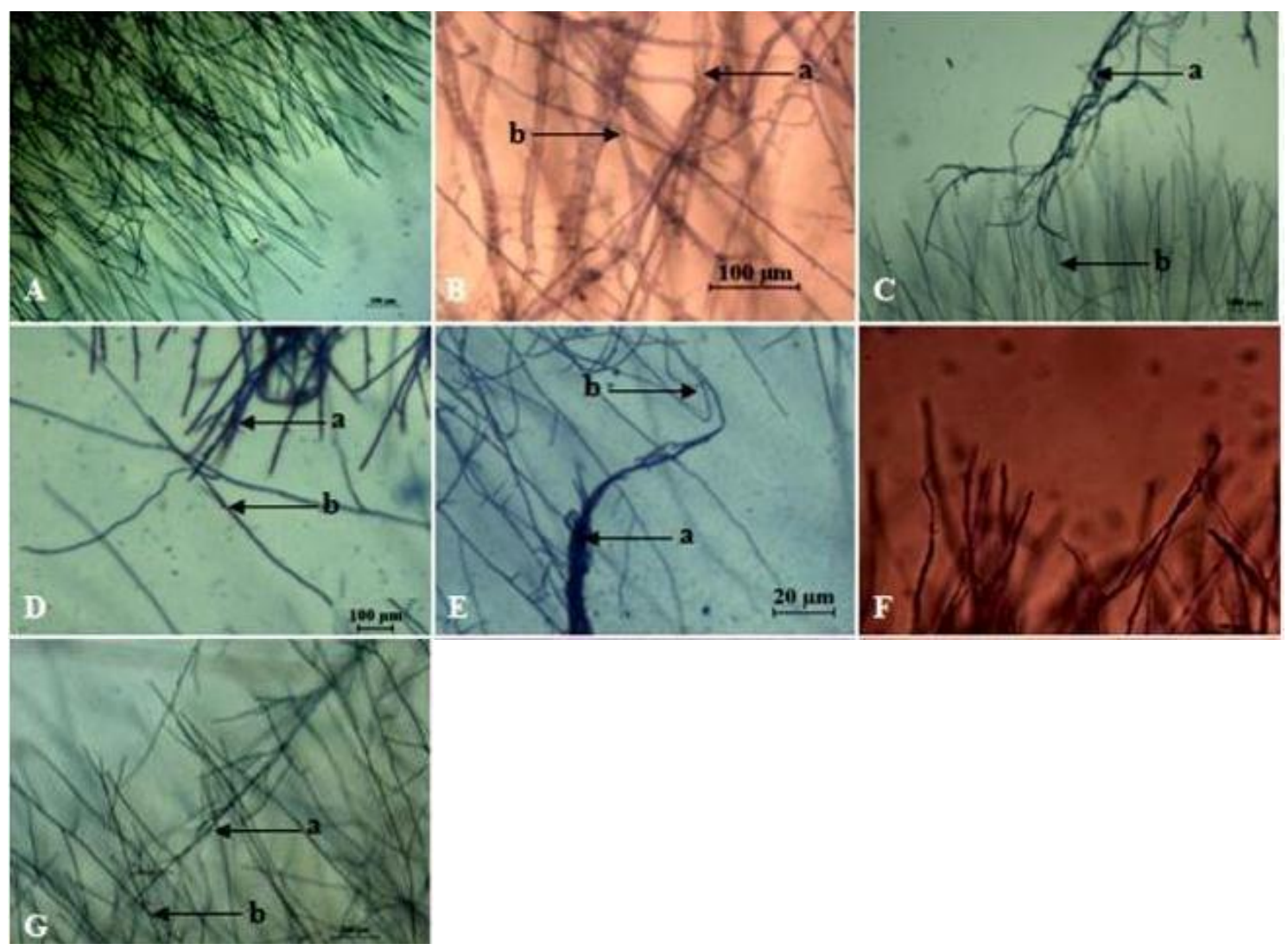

Figure 3. Interaction between endophytic fungi isolated from Solanum melongena and Fusarium oxysporum C2 (Fo); (A) normal Fo hyphae, (B) FEB1 and Fo hyphae, (C) FEB2 and Fo hyphae, (D) FEB5 and Fo hyphae, (E) FED1 and Fo hyphae, (F) Fo hypha becoming curly due to FED2 hyphae, (G) FED3 and Fo hyphae. (a) endophytic fungi (b) Fo

\section{Morphological characteristics of endophytic microbes with potential as antagonistic agents}

Characterization aimed to determine the macroscopic and microscopic characteristics of the endophytic microbes antagonistic to $F$. oxysporum. The observation of macroscopic features of the endophytic fungi showed that endophytic fungi have characteristics that can support their antagonistic activity; for example, exudate drops, aerial mycelia, and sclerotia. Exudate drops are the result of fungal metabolism that usually forms water droplets (Watanabe, 2002). The time when the exudate drops appear varies; there were some that appeared when the isolates were still at a young age (around 2-4 days after inoculation) or others at an old age (approximately 7 days and over). Isolates of the endophytic fungi appeared to produce antagonistically active compounds, except for FEB5 isolate.

A cluster of hyphae forms an intertwined mass called a mycelium that gets thicker through time and forms aerial hyphae or aerial mycelia (Gandjar et al. 2006). Endophytic fungal isolates that have a lot of aerial mycelia are highly benefited in terms of reproduction and dispersion. The fungal spores will quickly spread because the aerial mycelium can elongate and penetrate tissues inside the plant. In our study, isolates that had a lot of aerial hyphae were FEB1 and FED1 while the isolate that had only a few aerial hyphae was FED2.

Endophytic fungi form sclerotia at the relatively old age of about one month. Sclerotia are in the form of a hyphal mass that thickens and has a black color. According to Smith et al. (2014), the sclerotium is a structure that helps the fungi to survive against conditions such as freezing, desiccation, microbial attack, or the absence of the host. If the state of the environment is conducive, this resting cell will grow into hypha, mycelium, or stroma (Gandjar et al. 2006). Endophytic fungal isolates that had sclerotia in our study were FEB5 and FED3; they had a higher survival rate than other isolates.

The diameter of the endophytic fungi isolates was measured at 4 days after inoculation, at the time when one of the isolates had almost covered the surface of the PDA media in the Petri dishes. The diameters of the six antagonistic endophytic fungal isolates were larger (> 40 $\mathrm{mm})$ than the diameter of the Fo $(34.30 \mathrm{~mm})$, except for FED2 isolate that inhibited the Fo by antibiosis. The rate of growth of the endophytic fungi isolates was higher (10.36- 
$27.18 \mathrm{~mm} /$ day) when compared to the Fo pathogenic fungi $(8.85 \mathrm{~mm} /$ day), except for FED2 isolate $(5.11 \mathrm{~mm} /$ day $)$. Nevertheless, FED2 isolate was capable of producing active compounds to inhibit the growth of pathogenic fungi. With higher growth rates, the endophytic fungi can inhibit the growth of Fo. FEB1 was the isolate with the highest growth rate.

The colony shape of FEB 1 isolate was circular. The color of the surface and reverse side of the colony color was yellow; it had a cottony texture and exudates drops. On the fourth day, the colony diameter was $73.8 \mathrm{~mm}$. Hyphae of FEB1 were septate. Spores were semi-spherical, and they were arranged inside a sporangium supported by a sporangiophore. There was a root-like structure called a rhizoid (Figure 4).

The colony shape of isolate FEB2 was circular. The surface of the colony was white in color, while the reverse side was gray to black. The colony had a cottony texture, with exudates drops. On the fourth day, the colony diameter was $81.87 \mathrm{~mm}$. Hyphae of FEB2 were septate. Its spore type was a helicospore supported by a conidiophore (Figure 5).

Isolate FEB5 was irregular in colony shape. The diameter of the colony was $60.25 \mathrm{~mm}$ on the fourth day. The color of the surface and reverse side of the colony both were white. The texture of the colony was cottony. Hyphae of FEB5 were septate and the spore type was a helicospore (Figure 6). This isolate formed sclerotia when the medium was running low (Figure 7).
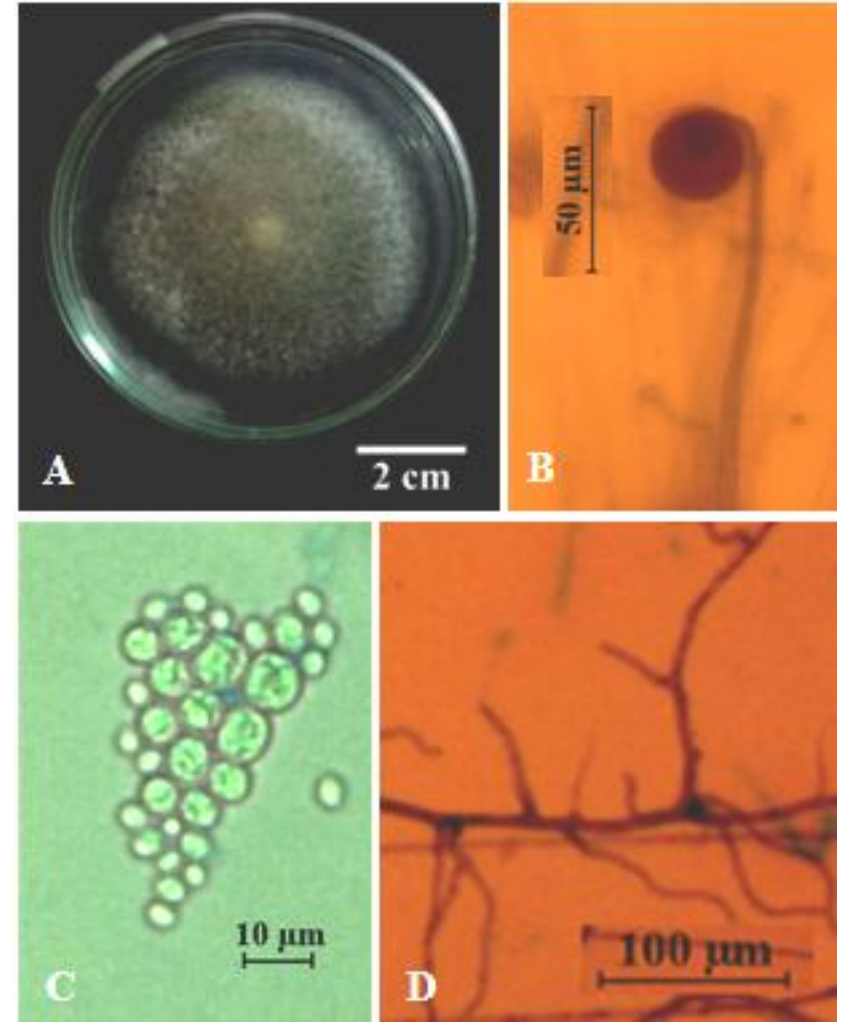

Figure 4. Isolate FEB1; (A) FEB1 colony on PDA medium after four days of incubation (B) sporangium supported by sporangiophore (C) spores (D) rhizoids.
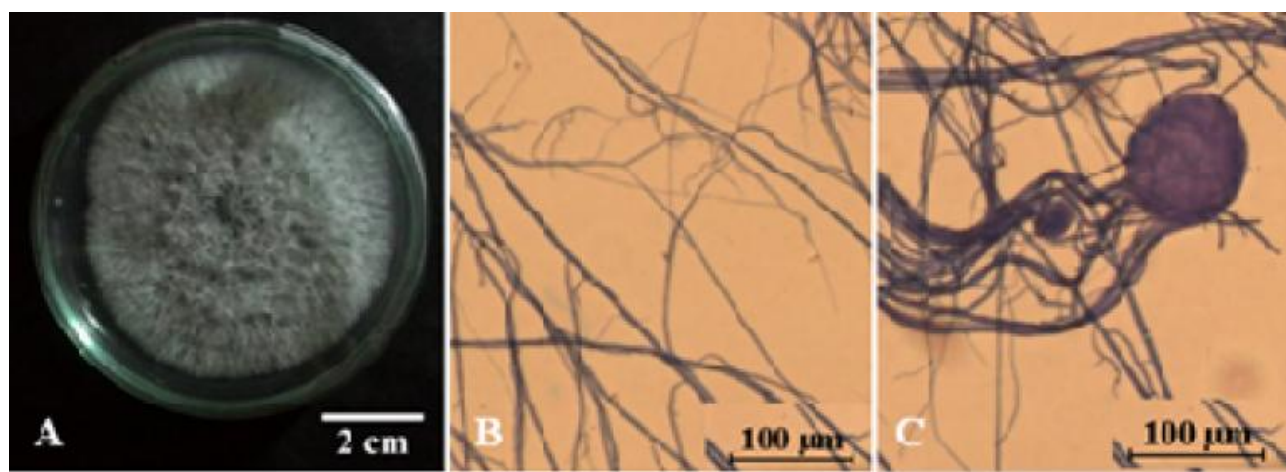

Figure 5. Isolate FEB2; (A) FEB2 colony on PDA medium after four days of incubation (B) hyphae (C) helicospore
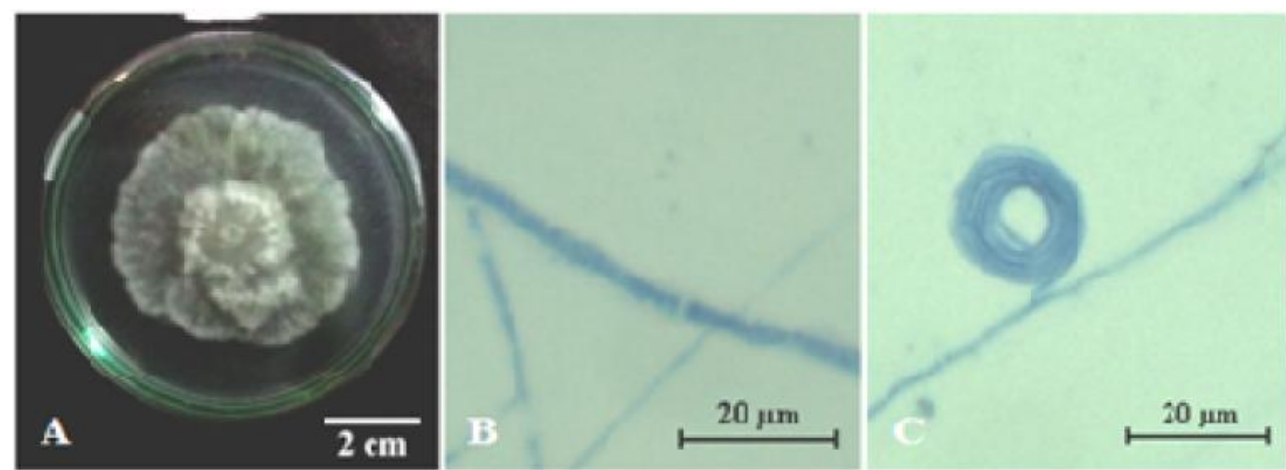

Figure 6. Isolate FEB5; (A) FEB5 colony on PDA medium after four days of incubation, (B) hypha, (C) helicospore. 

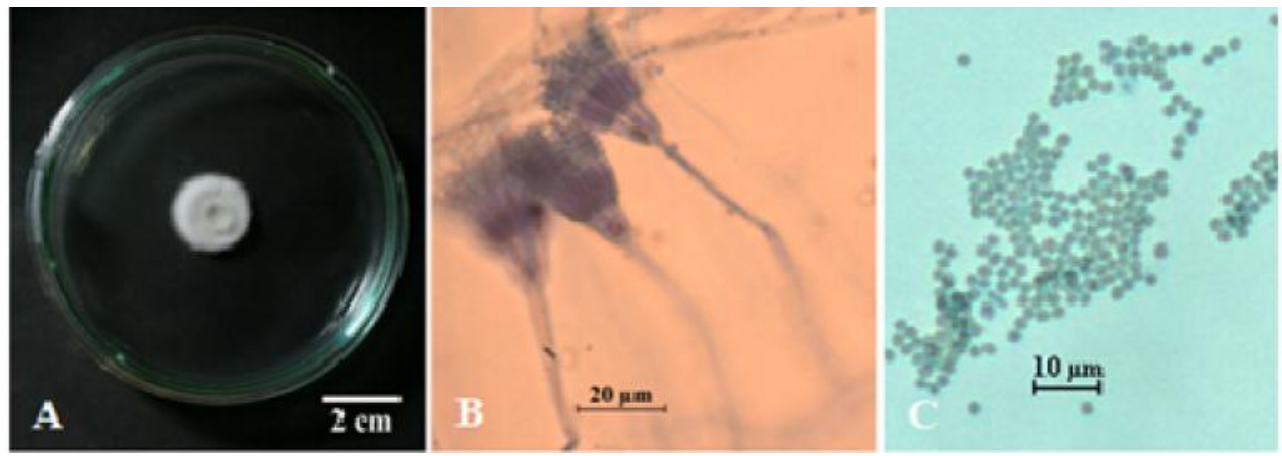

Figure 9. Isolate FED2; (A) FED2 colony on PDA medium after four days of incubation (B) conidiophore branching (C) conidiospores
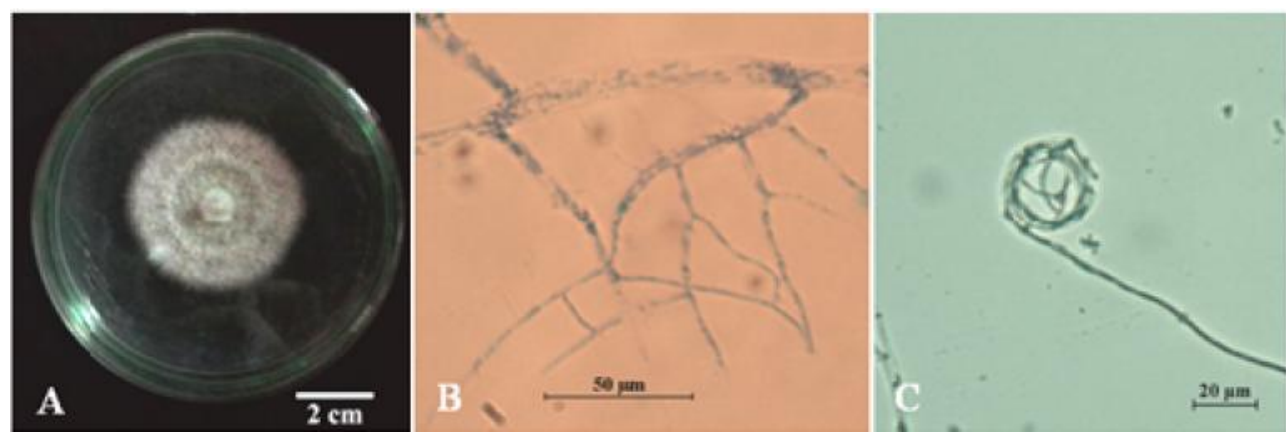

Figure 10. Isolate FED3; (A) FED3 colony on PDA media after four days of incubation, (B) hyphae, (C) helicospore
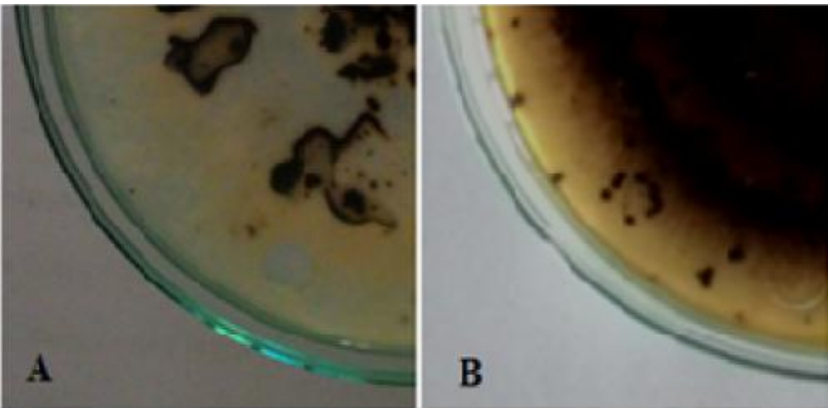

Figure 7. Sclerotia of FEB5 (A) and FED3(B)

Isolate FED1 had an irregular colony shape with a colony diameter of $73.95 \mathrm{~mm}$ on the fourth day. The color of the surface and reverse side of the colony both were yellow. The surface of the colony was cottony in texture, and there were exudate drops present. Hyphae were septate. Spores were produced in a sporangium. Spore shape was oblong (Figure 8). FED1 was similar to FEB1, except that FED1 did not have a rhizoid.

Isolate FED2 formed a circular colony with a velvety texture and exudates drops. Colony diameter was 19.67 $\mathrm{mm}$ on the fourth day. The color of the young colony was white and the mature colony was dark green. The reverse side of the young colony was pinky white in color, while the reverse of the mature colony was green white. Conidia were supported by mono-verticillate conidiophores. Conidiospores were round in shape (Figure 9).

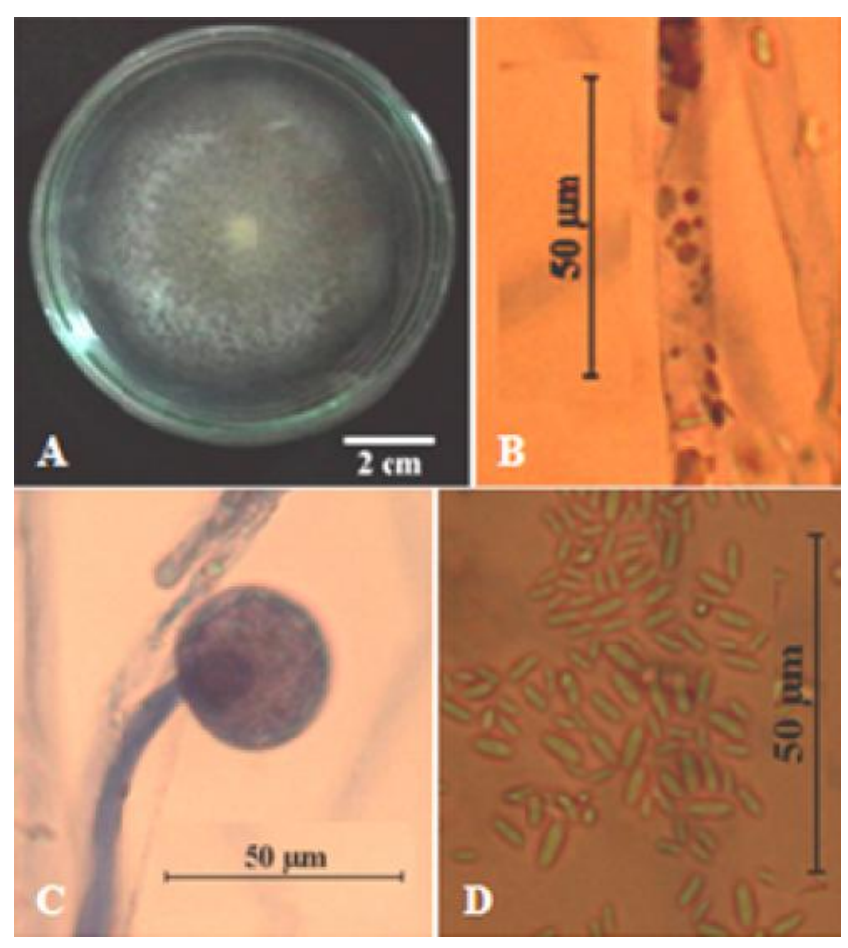

Figure 8. Isolate FED1; (A) FED1 colony on PDA medium after four days of incubation, (B) hypha (C) sporangium, (D) spores

Isolate FED3 formed a circular colony with cottony texture and exudates drops. The colony diameter was 48.1 
$\mathrm{mm}$ on the fourth day. The color of the colony surface was white, and the color of the reverse side of the young colony was light brown while the mature colony reverse side was dark brown. Like FEB5, isolate FEB3 also formed sclerotia when the medium was running low. Its spore type was a helicospore (Figure 10).

From the characterization results, the genera of the endophytic fungi isolates could be determined, particularly considering the shapes of their asexual spores/conidia. Isolates FEB2, FEB5, and FED3 were identified as Helicomyces spp.; FEB1 was a Rhizopus sp.; FED1 a Mucor sp., and FED2 a Penicillium sp.

\section{ACKNOWLEDGEMENTS}

We are grateful to Dr. Supyani from the Laboratory of Plant Pests and Diseases, Faculty of Agriculture, Universitas Sebelas Maret, Surakarta, Indonesia who collected and gave his Fusarium isolates to be further investigated.

\section{REFERENCES}

Aer BN, Wullur AC, Citraningtyas G. 2013. Test of the effect of ethanol extract of purple eggplant (Solanum melongena L.) on blood glucose level in white male rats Wistar strain (Rattus norvegicus). Pharmacon 2 (4): 135-141. [Indonesian]

Agrios GN. 1988. Plant Pathology. 3rd ed. Academic Press, NY, USA.

Andersen CR. 2011. Home Gardening Series: Eggplant. Agriculture and Natural Resource, University of Arkansas, Fayetteville, AR, USA

Central Bureau of Statistics. 2015. Eggplant Production from Year 2010 to 2014. www.bps.go.id. [Indonesian]

Baker KF, Cook RJ. 1983. Biological Control of Plant Pathogen. Freeman and Co., San Fransisco.

Balouiri M, Sadiki M, Ibnsouda SK. 2015. Methods for in vitro evaluating antimicrobial activity: A Review. J Pharmaceut Anal 6 (2016): 71-79.

Berlian I, Setyawan B, Hadi H. 2013. Antagonist mechanism of Trichoderma spp. against some soil contagious pathogens. Warta Perkaretan 32 (2): 74-82. [Indonesian]

Daunay MC., Janick J.. 2007. History and iconography of eggplants. Chronida Hort 47 (3): 16-22.

Delahaut KA, Newenhouse AC. 1997. Growing tomatoes, peppers, and eggplants in Wisconsin: A guide for fresh-market growers. Cooperative Extension Publishing, Wisconsin.
Dikilitas M, Kocyigit A. 2010. Mononuclear leukocyte DNA damage on higher cells caused by eco-friendly pesticides and their analysis using CASP® programme. Agric Fac HRU 14 (4): 47-56.

Dolakatabadi HK, Goltapeh EM, Mohammadi N, Rabiey M, Rohani N, Varma. 2012. Biocontrol potential of root endophytic fungi and Trichoderma species against Fusarium wilt of lentil under in vitro and greenhouse conditions. J Agr Sci Tech 14: 407-420.

Erica O. 2011. Eggplant. Department of Agriculture, Forestry and Fisheries, Pretoria, South Africa.

Fayzalla EA, Shabana YM, Mahmoud NS. 2008. Effect of environmental conditions on wilting and root rot fungi pathogenic to solanaceous plants. Plant Pathol J 7(1): 27-33.

Gandjar I, Samson RA, Tweel-Vermeulen K, Oetari A, Santoso I. 1999. Introduction to General Tropical Molds. Yayasan Obor Indonesia, Depok. [Indonesian]

Gandjar I, Sjamsuridzal W, Oetari A. 2006. Mycology: Basic and Applied. Yayasan Obor Indonesia, Depok. [Indonesian]

Khrueayu D, Pilantanapak A. 2012. Antifungal activity of bioactive compound from endophytic fungi isolated from mangrove leaves. 1st Mae Fah Luang University International Conference 2012. 1-6.

Kumar S, Aharwal RP, Shukla H, Rajak RC, Sandhu SS. 2014. Endophytic fungi: as a source of antimicrobials bioactive compounds. World J Pharm Pharm Sci 3(2): 1179-1197

Kurnia AT, Pinem MI, Oemry S. 2014. Use of endophytic fungus to control Fusarium oxysporum f.sp. capsici and Alternaria solani in vitro. Jurnal Online Agroekoteknologi. 2 (4): 1596 - 1606. [Indonesian]

Ramesh R, Phadke GS. 2012. Rhizosphere and endophytic bacteria for the suppression of eggplant wilt caused by Ralstonia solanacearum. Crop Protect 37 (2012): 35-41.

Rodriguez RJ, White Jr JE, Arnold AE, Redman RS. Fungal endophytes: diversity and functional roles. New Phytopathologist. 2009. DOI: 10.111/j.1469-8137.2009.02773

Shabana MM, Salama MM, Ezzat SM, Ismail LR. 2013. In vitro and in vivo anticancer activity of the fruit peels of Solanum melongena $\mathrm{L}$. against hepatocellular carcinoma. J Carcino Mut 4 (3): 1-6.

Sharma D, Kaur T, Chadha BS, Manhas RJ. 2011. Antimicrobial activity of actinomycetes against multidrug-resistant Staphylococcus aureus, Escherichia coli, and various pathogens. Trop J Pharm Res 10 (6): 801-808.

Smith ME, Henkel TW, Rollins JA. 2014. How many fungi make sclerotia? Fungal Ecol. DOI: 10.1016/j.funeco.2014.08.010.

Strobel G, Daisy B. 2003. Bioprospecting for microbial endophytes and their natural products. Microbiol Mol Biol Rev. DOI: 10.1128/MMBR.67.4.491-502.2003

Watanabe T. 2002. Pictorial atlas of soil and seed fungi: morphologies of cultured fungi and key to species Second Edition. CRC Press, USA.

Yildiz HN, Altinok HH, Dikilitas M. 2012. Screening of rhizobacteria against Fusarium oxysporum f. sp. melongenae, the causal agent of wilt disease of eggplant. African J Microbiol Res. 6 (15): 3700-3706.

Živković S, Stojanović S, Ivanović Ž, Gavrilović V, Popović T, Balaž J. 2010. Screening of antagonistic activity of microorganisms against Colletotrichum acutatum and Colletotrichum gloeosporioides. Arch Biol Sci Belgrade 62: 611-623. 